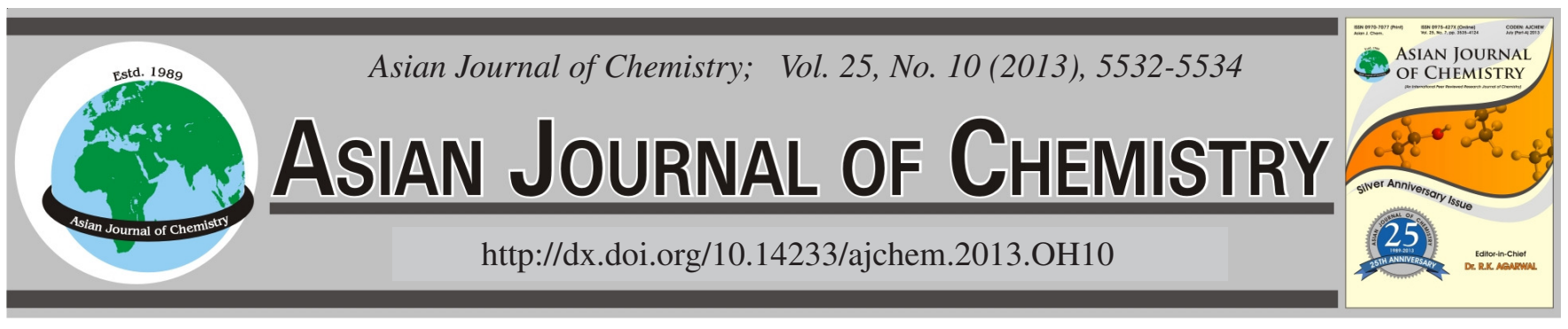

\title{
Influence of Restraint on Pore Structures and Air Permeability of Concrete Containing MgO-Type Expansive Agent $\uparrow$
}

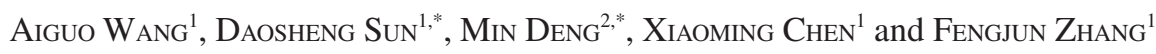

${ }^{1}$ Anhui Key laboratory of Advanced Building Materials, Anhui University of Architecture, Hefei 230022, Anhui Province, P.R. China

${ }^{2}$ State Key Laboratory of Materials-Oriented Chemical Engineering, Nanjing University of Technology, Nanjing 210009, P.R. China

*Corresponding author: Fax: +86 551 3828078; +86 25 83172110; E-mail: sundaosheng@163.com; dengmin@njut.edu.cn

AJC-13252

\begin{abstract}
The effect of restraint on pore structures and air-permeability of concrete containing MgO-type expansive agent was investigated in the paper. Pore structures of mortars in sided center and cubical center of concrete were analyzed using mercury intrusion porosimetry. The porosity and air-permeability of concrete were determined by method of evaporated water and Torrent permeability tester, respectively. The results show that restraint decreases porosity and pore size and improves pore size distribution of mortars in concrete containing $\mathrm{MgO}$-type expansive agent. The improvement of pore structures in concrete matrix tends to increase density and decrease air-permeability of concrete containing $\mathrm{MgO}$-type expansive agent.
\end{abstract}

Key Words: Restraint, MgO-type expansive agent, Concrete, Pore structure, Air-permeability.

\section{INTRODUCTION}

Cracking of concrete induced by its volume shrinkage is one of usual types of damage, which may accelerate other deteriorations and even cause function loss of materials. As a result, more attentions have been paid to reduce and improve volume stability of concrete. Many measures have been suggested to reduce the shrinkage and the shrinkage compensation one of effective measures ${ }^{1,2}$. MgO-type expansive agent is a novel expansive additive, which has advantages of less requirements for wet curing, high stability of the hydration product $\mathrm{Mg}(\mathrm{OH})_{2}$ and easy adjustment of expansion process ${ }^{3}$. Proper expansion generated by $\mathrm{MgO}$-type expansive agent can not only improve volume stability, but also enhance mechanical properties, permeability and freezing-thawing resistance of concrete $^{3}$. Role of MgO-type expansive agent is usually influenced by reactivity of $\mathrm{MgO}$-type expansive agent, curing environment and restrained condition. The relationships among environmental condition, microstructure and property of concrete are not yet fully developed. Research on the relationships between microstructure and property of high performance expansive concrete under restrained condition is absent. The permeability and porosity of concrete have been recognized as major factors in determining durability of concrete structures $^{4}$. This paper reports the effect of restraint on pore derived from expansion generated by expansive additives is

structures and air-permeability of concrete containing $\mathrm{MgO}$ type expansive agent.

\begin{tabular}{l} 
EXPERIMENTAL \\
\hline P.II42.5R Portland cement produced by Nanjing-China \\
Cement Corp., Jiangsu, China was used. Coarse aggregate was \\
5 -31.5 mm continuous gradation crushed limestone with $9.5 \%$ \\
smashing index and less than $0.5 \%$ silt. Fine aggregate was \\
river sand with a fineness module of 2.7 and $1 \%$ silt. MgO- \\
type expansive agent and JM-B naphthalene superplasticizer \\
were used as the admixtures. Chemical compositions of cement \\
and MgO-type expansive agent are shown in Table- 1 . Tap water \\
was used as mixing water. \\
Mixture proportion of concrete by weight is showed in \\
Table-2. Six concrete cube specimens with size of 150 mm $\times$ \\
150 mm $\times 150$ mm were cast. Half of concrete specimens \\
were demolded at 24 h after concrete was cast. Another half \\
of concrete specimens were not demolded until test was carried. \\
All specimens were directly immersed in water at $20 \pm 2{ }^{\circ} \mathrm{C}$ \\
for 365 days. \\
Pore structures of mortars in concrete were measured by \\
MIP. Mortars in the form of pellets of about 6 mm in diameter \\
were obtained from sided center and cubical center of concretes \\
with restraint and unrestraint. They were then dried in a vacuum \\
oven at $60{ }^{\circ} \mathrm{C}$ for 48 h. Air-permeability of concrete was \\
determined with a Torrent permeability tester ${ }^{5,6}$.
\end{tabular}

$†$ Presented to the 6th China-Korea International Conference on Multi-functional Materials and Application, 22-24 November 2012, Daejeon, Korea 
TABLE-1

CHEMICAL COMPOSITIONS OF CEMENT AND MgO-TYPE EXPANSIVE AGENT (MEA) USED (Wt) \%

\begin{tabular}{ccccccccccc}
\hline Materials & $\mathrm{SiO}_{2}$ & $\mathrm{Al}_{2} \mathrm{O}_{3}$ & $\mathrm{Fe}_{2} \mathrm{O}_{3}$ & $\mathrm{CaO}$ & $\mathrm{MgO}$ & $\mathrm{SO}_{3}$ & $\mathrm{Na}_{2} \mathrm{O}$ & $\mathrm{K}_{2} \mathrm{O}$ & Loss & Total \\
\hline Cement & 21.27 & 5.16 & 3.46 & 64.35 & 0.95 & 2.01 & 0.08 & 0.55 & 1.26 & 99.09 \\
MEA & 0.83 & 0.37 & 0.80 & 3.98 & 91.70 & $/$ & $/$ & $/$ & 1.98 & 99.66 \\
\hline
\end{tabular}

TABLE-2

MIXTURE PROPORTION OF CONCRETE BY WEIGHT $\left(\mathrm{kg} / \mathrm{m}^{3}\right)$

\begin{tabular}{cccccc}
\hline Cement & Water & $\begin{array}{c}\text { Fine } \\
\text { aggregate }\end{array}$ & $\begin{array}{c}\text { Coarse } \\
\text { aggregate }\end{array}$ & MEA & $\begin{array}{c}\text { Super } \\
\text { plasticizer }\end{array}$ \\
\hline 340 & 143 & 610 & 1425 & 27.2 & 2.75 \\
\hline
\end{tabular}

$75 \mathrm{~mm} \times 75 \mathrm{~mm} \times 50 \mathrm{~mm}$ specimens used for measurement of porosity were cut from concretes. These specimens were thoroughly washed and immersed in water for $48 \mathrm{~h}$. They were removed from water, wiped up for a saturated surfacedry state with a large absorbent cloth and weighed the mass $\left(\mathrm{w}_{1}\right)$. Volume of specimens was measured using Archimedes drainage method. These specimens were then dried at $60^{\circ} \mathrm{C}$ and weighed the mass $\left(\mathrm{w}_{\mathrm{t}}\right)$ once every $0.5 \mathrm{~h}$, up to $7.5 \mathrm{~h}$. They were then dried at $105{ }^{\circ} \mathrm{C}$ to a near constant mass, cooled in air and reweighed the mass $\left(\mathrm{w}_{2}\right)$. The water weight loss on drying was converted to volume fraction of the bulk concrete ${ }^{7,8}$. The porosity of concrete was calculated by eqn. (1), the evaporation capacity of water in concrete was calculated by eqn. (2).

$$
\begin{aligned}
& \mathrm{P}=\frac{\left(\mathrm{w}_{1}-\mathrm{w}_{2}\right)}{\mathrm{V} \rho} \times 100 \% \\
& \mathrm{E}=\frac{\left(\mathrm{w}_{1}-\mathrm{w}_{\mathrm{t}}\right)}{\left(\mathrm{w}_{1}-\mathrm{w}_{2}\right)} \times 100 \%
\end{aligned}
$$

where $\mathrm{P}$ is the porosity of concrete; $\mathrm{E}$ is the evaporation capacity of water in concrete; $\mathrm{V}$ is the volume of saturated surface-dry concrete; $\rho$ is the density of water, being $1 \mathrm{~g} / \mathrm{cm}^{3}$.

\section{RESULTS AND DISCUSSION}

Effect of restraint on pore structures of mortars in concrete: The influence of restraint and unrestraint on porosity of mortars in sided center and cubical center of concrete containing MgO-type expansive agent is shown in Table-3. In comparison with unrestrained concrete, the porosity of mortar in cubical center and sided center of restrained concrete was decreased by $5.7 \%$ and $1.8 \%$, respectively. Compared with sided center of concrete, the porosity of mortars in cubical center of concrete with restraint and unrestraint was decreased by $18.1 \%$ and $14.7 \%$, respectively.

\begin{tabular}{lcc}
\multicolumn{3}{c}{ TABLE-3 } \\
\multicolumn{3}{c}{$\begin{array}{c}\text { POROSITY OF MORTARS IN CONCRETE CONTAINING } \\
\text { MEA WITH RESTRAINT AND UNRESTRAINT }\end{array}$} \\
\hline Samples & $\begin{array}{c}\text { Porosity of mortar in } \\
\text { cubical center }(\%)\end{array}$ & $\begin{array}{c}\text { Porosity of mortar } \\
\text { in sided center }(\%)\end{array}$ \\
\hline Restrained concrete & 9.35 & 11.42 \\
Unrestrained concrete & 9.92 & 11.63 \\
\hline
\end{tabular}

The expansion of cement paste in concrete containing $\mathrm{MgO}$-type expansive agent is caused by the self-expansion of $\mathrm{MgO}$-type expansive agent which is attributed to $\mathrm{Mg}(\mathrm{OH})_{2}$ formation $^{3}$. The results show that restraint decreases porosity of mortars in concrete containing MgO-type expansive agent. Porosity of mortar in cubical center is less than that of mortar in sided center of concrete containing MgO-type expansive agent with restraint and unrestraint, which indicates that there is "self-restricted effect" in concrete. The restricted effect depends upon restrictions of aggregate, especially coarse aggregate ${ }^{9}$.

Fig. 1 shows the per cent of pore volume of mortars in sided center and cubical center of concrete containing MgOtype expansive agent with restraint and unrestraint. Pores in mortars may be classified as more harmful pore (pore diameter $\mathrm{d}>200 \mathrm{~nm})$, harmful pore $(50-200 \mathrm{~nm})$, a less harmful pore $(20-50 \mathrm{~nm})$ and harmless pore $(\mathrm{d}<20 \mathrm{~nm})^{10}$. The per cent of a less harmful pore of mortars in sided center and cubical center of concrete with restraint and unrestraint exceeds $47 \%$ and the per cent of pore volume of mortar in cubical center is larger than that of mortar in sided center of concrete containing MgOtype expansive agent with restraint and unrestraint, increased by $25.6 \%$ and $7.5 \%$, respectively. In comparison with unrestrained concrete, the per cent of a less harmful pore of mortar in cubical center of restrained concrete is increased by $13.5 \%$, the per cent of pore volume with pore larger than $50 \mathrm{~nm}$ in diameter is decreased by $19.4 \%$.

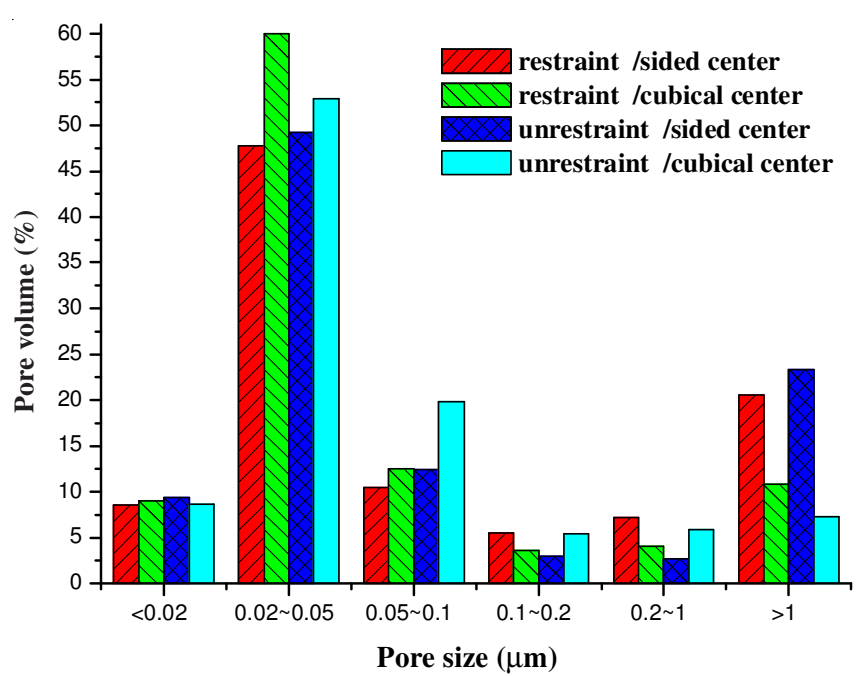

Fig. 1. Percentage of pore volume of mortar in sided center and cubical center of concretes containing $\mathrm{MgO}$-type expansive agent

In comparison with unrestrained concrete, restrained concrete was restricted by steel mould and self-restraint conditions. The per cent of pore volume with pore larger than 50 $\mathrm{nm}$ in diameter of mortar in cubical center of restrained concrete is evidently reduced and a little harmful pore is increased. The results indicate that restraint tends to decrease pore size of mortars in concrete containing MgO-type expansive agent.

Effect of restraint on pore and air-permeability of concrete: The effect of restraint on porosity and air-permeability of concrete containing MgO-type expansive agent is shown in Table-4. The water-saturated porosity and air-permeability of concrete were determined by method of evaporated water 
TABLE-5

EFFECTS OF RESTRAINT ON EVAPORATION CAPACITY OF WATER IN CONCRETE

\begin{tabular}{lcccccc}
\hline Samples & $\mathrm{A}$ & $\mathrm{B}$ & $\mathrm{C}$ & $\mathrm{R}^{2 *}$ & $\mathrm{El}_{\mathrm{t}=7.5 \mathrm{~h}}[\%]$ & $\left.\mathrm{t}\right|_{\mathrm{E}=21 \%}[h]$ \\
\hline Unrestrained concrete /lateral specimens & 2.012 & 4.841 & -0.274 & 0.998 & 22.89 & 5.88 \\
Restrained concrete /lateral specimens & 2.354 & 4.509 & -0.244 & 0.996 & 22.46 & 6.24 \\
Unrestrained concrete /middle specimens & 1.831 & 4.586 & -0.254 & 0.998 & 21.95 & 6.57 \\
Restrained concrete /middle specimens & 2.609 & 4.182 & -0.220 & 0.997 & 21.61 & 6.90 \\
\hline${ }^{*}$ Where $\mathrm{R}^{2}$ is coefficient of determination & & & & & &
\end{tabular}

and Torrent permeability tester, respectively. Compared with unrestrained concrete, porosity, permeability coefficient $\mathrm{K}_{\mathrm{t}}$ and depth of penetration $\mathrm{L}$ of restrained concrete is decreased by $8.3,8.1$ and $7.2 \%$, respectively.

\begin{tabular}{lccc}
\hline \multicolumn{3}{c}{ TABLE-4 } \\
EFFECT OF RESTRAINT ON POROSITY AND \\
AIR-PERMEABILITY OF CONCRETE \\
\hline \multirow{2}{*}{ Samples } & $\begin{array}{c}\text { Porosity of } \\
\text { concrete }(\%)\end{array}$ & Air-permeability of concrete \\
\cline { 2 - 4 } & 5.08 & $\mathrm{~K}_{\mathrm{T}}\left[\times 10^{-16} \mathrm{~m}^{2}\right]$ & $\mathrm{L}[\mathrm{mm}]$ \\
\hline Restrained concrete & 0.226 & 32.1 \\
Unrestrained concrete & 5.54 & 0.246 & 34.6 \\
\hline
\end{tabular}

Quadratic polynomial curves fitting to data points relating evaporation capacity of water in restrained and unrestrained concrete containing $\mathrm{MgO}$-type expansive agent and time are shown in Fig. 2. For the equation of quadratic polynomial curve fitting $\left(\mathrm{E}=\mathrm{A}+\mathrm{B} \times \mathrm{t}+\mathrm{C} \times \mathrm{t}^{2}\right)$, assume that $\mathrm{t}=7.5 \mathrm{~h}$ or $\mathrm{E}=21$ $\%$ respectively, then $\mathrm{E} / \mathrm{t}=7.5 \mathrm{~h}=\mathrm{A}+7.5 \mathrm{~B}+56.25 \mathrm{C}$, or $\left.\mathrm{t}\right|_{\mathrm{E}=21 \%}=\frac{-\mathrm{B}+\sqrt{\mathrm{B}^{2}-4 \mathrm{C}(\mathrm{A}-21)}}{2 \mathrm{C}}$, accordingly. Calculational results are given in Table-5.

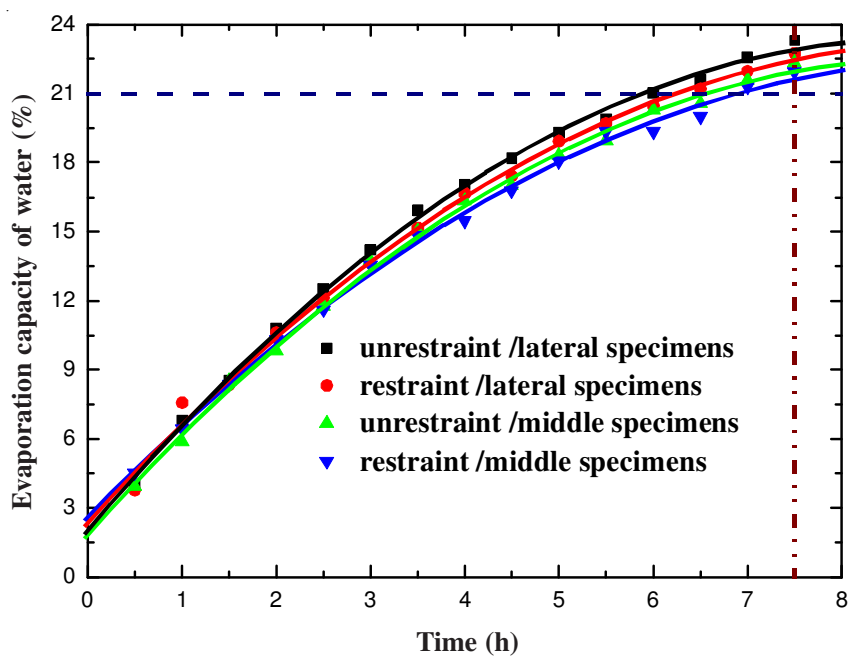

Fig. 2. Evaporation capacity of water at $60^{\circ} \mathrm{C}$ in concretes

Compared with unrestrained concrete, as concrete was dried for $7.5 \mathrm{~h}$ at $60^{\circ} \mathrm{C}$, evaporation capacity of water in specimens of lateral part and middle part for restrained concrete containing MgO-type expansive agent is decreased by $1.9 \%$ and $1.5 \%$, respectively. On the other hand, when evaporation capacity of water is $21 \%$, the time required for evaporation is increased by $6.1 \%$ and $5.0 \%$, respectively.
The results indicate that restrained concrete containing MgO-type expansive agent shows lower porosity and airpermeability and improvement of pore structures in mortar is consistent with the changing of porosity and air-permeability of concrete.

\section{Conclusion}

Restraint may decrease porosity and pore size of concrete containing $\mathrm{MgO}$-type expansive agent. In comparison with unrestrained concrete, the porosity of mortar in cubical center of restrained concrete was decreased by $5.7 \%$, the percent of pore volume with pore larger than $50 \mathrm{~nm}$ in diameter is decreased by $19.4 \%$.

The improvement of pore structures of mortars in concrete may increase density and impermeability of restrained concrete containing MgO-type expansive agent. Compared with unrestrained concrete, porosity, permeability coefficient $\mathrm{K}_{\mathrm{t}}$ and depth of penetration $\mathrm{L}$ of restrained concrete is decreased by $8.3,8.1$ and $7.2 \%$, respectively.

\section{ACKNOWLEDGEMENTS}

This research is financially supported by the Nature Science Foundation of Education Agency of Anhui Province (KJ2012A052), the Anhui Provincial Natural Science Foundation (1208085ME82 and 1308085QE88), the Doctor Fund of Anhui Institute of Architecture and Industry (20123302) and the Open Project from Research Institute for Building Energy Efficiency of Anhui University of Architecture (20123211 and 20123208).

\section{REFERENCES}

1. C. Maltese, C. Pistolesi, A. Lolli, A. Bravo, T. Cerulli and D. Salvioni, Cement Concrete Res., 35, 2244 (2005).

2. S.G. Hu and Y. Li, Cement Concrete Res., 29, 1013 (1999).

3. L.W. MO, Microstructure and Property of MgO-type Expansive Agent. Nanjing: Nanjing University of Technology (2008) (in Chinese).

4. P.K. Mehta, Concrete: Microstructure, Properties and Materials, New York: MeGraw Hill, edn. 3 (2005).

5. R. Torrent, Mater. Struct., 25, 358 (1992).

6. A.G. Wang, M. Deng, D.S. Sun, L.W. Mo and M.S. Tang, J. Wuhan Univ. Technol.-Mater. Sci., 26, 786 (2011).

7. V.T. Ngala and C.L. Page, Cement Concrete Res., 27, 995 (1997).

8. J. Liu, Y. Tian and Z. Liu, J. Shengyang Jianzhu Univ. (Nat. Sci.), 23, 597 (2007) (in Chinese).

9. M. Saito, M. Kawamura and S. Arakawa, Cement Concrete Res., 13, 115 (1991).

10. Z.W. Wu and H.Z. Lian, High Performance Concrete, Beijing: Chinese Railway Press (1999) (in Chinese). 